\title{
Occupational exposure, knowledge of standard precautions and behavior among health workers in Southern Nigeria
}

\author{
Samuel Ereh
}

From International Symposium HIV and Emerging Infectious Diseases 2014

Marseille, France. 21-23 May 2013

\section{Background}

Developing countries account for the highest prevalence of HIV-infected patients in the world and also record the highest needlestick injuries. The objective of this study was to assess the exposure, knowledge and practices of standard precautions among Health care workers (HCWs) in Southern Nigeria.

\section{Methods}

We surveyed 212 HCWs in 4 state-owned hospitals and 25 local government primary health centers. Structured questionnaires were utilized. Descriptive statistics and multivariate analysis using logistic regression were done.

\section{Results}

$57.7 \%$ of respondents were aware of the term Standard Precautions (SPs) overall. Doctors (94.4\%) and nurses $(84.2 \%)$ had the highest levels of awareness compared to $3.0 \%$ of health assistants. There was a significant relationship between the respondents' level of education and a correct knowledge of SPs. (Fisher's Exact $=125.745, \mathrm{df}=4$, $\mathrm{p}=0.000)$ and duration of employment was not significantly associated with the awareness of SPs. ( $x 2=5.676$, $\mathrm{df}=3, \mathrm{p}=0.128)$. Life time risks of needle stick (39.8\%; 95\% CI 36.4-44.6\%) and sharps injuries (25.7\%; 95\% CI 21.8-29.6\%) were high. $77.8 \%$ washed their hands at the close of work. Over half (56.6\%) always used gloves and two-thirds (62.3\%) had never worn goggles during contact with blood and body fluids. Only $46.2 \%$ of HCWs reported washing their hands before each patient contact. Overall compliance with non-recapping of used needles was generally poor (14.6\%) and about half (48.1\%) of the respondents recapped used needles before disposal. The one year

Eku Baptist Hospital, Department of Family Medicine, Eku, Nigeria prevalence of needle stick and sharps injury were $29.3 \%$ (95\% CI 26.7-32.8\%) and 22.9\% (95\% CI 19.8-25.2\%) respectively.

\section{Conclusions}

The poor knowledge and non-compliance with SPs among the HCWs placed them at significant health risks. Adequate supply of protective equipment with regular training programs should therefore be put in place to promote appropriate use by the HCWs at all times.

Published: 23 May 2014

doi:10.1186/1471-2334-14-S2-P8

Cite this article as: Ereh: Occupational exposure, knowledge of standard precautions and behavior among health workers in Southern Nigeria. BMC Infectious Diseases 2014 14(Suppl 2):P8.

Submit your next manuscript to BioMed Central and take full advantage of:

- Convenient online submission

- Thorough peer review

- No space constraints or color figure charges

- Immediate publication on acceptance

- Inclusion in PubMed, CAS, Scopus and Google Scholar

- Research which is freely available for redistribution 